\title{
Research Article Significance of Human Papilloma Virus genotyping in cervical cancer screening
}

\author{
Sharma $\mathbf{P}^{1}$, Sharma $\mathbf{S}^{2}$, Arti ${ }^{3}$ \\ ${ }^{1}$ Dr Poonam Sharma, Associate Professor, ${ }^{2}$ Dr Sarabjeet Sharma, Professor \& Head, Department of Microbiology, \\ ${ }^{3}$ Mrs Arti, Tutor; all authors are affiliated with Department of Microbiology, Sri Guru Ram Das Institute of Medical \\ Sciences \& Research, Amritsar, Punjab, India.
}

Address for Correspondence: Dr Poonam Sharma, Email: poonam136@ rediffmail.com

\begin{abstract}
Background and Objectives: Detection of specific human papillomavirus (HPV) genotypes may be useful for identifying those women who are at lower and higher risk for cervical precancer and cancer. Cervical cancer is the most common cancer and leading cause of cancer deaths in women in developing countries. Therefore, the present study was undertaken with the aim of identifying the most frequent HPV genotypes associated with different cervical lesions. Materials and Methods: The study was a retrospective cross-sectional study conducted over a period of one and a half years i.e. from January 2015 to July 2016, on women attending obstetrics and gynaecology department of a tertiary care hospital. One hundred eighty three consecutive scrape samples or cervical brushings were collected from women presenting with any type of cervical lesions. DNA was extracted from the clinical sample using Hybribio DNA extraction kit. Hybribio HPV genoarray test kit was used to genotype the HPV risk groups. Results: Out of 183 cervical brushings collected over a period of one and a half years, $22(12 \%)$ were positive for HPV genotypes. Among the latter, HPV18 genotype was observed in $12(54.5 \%)$, HPV16 genotype in $3(13.6 \%)$ and HPV53 genotype in 2 (9.09\%). One of the genotypes 68, 52, 39, 33 and 56 were present in rest of the samples. Conclusion: Most common genotypes associated with cervical lesions in the present study were genotype 18 followed by 16 which shows that cervical cancer screening should rely on measuring the causal viral infection, oncogenic HPV, rather than the pleomorphic cellular changes caused by the infection
\end{abstract}

Key words: HPV, Cervical cancer, Screening, Genotyping, Significance

\section{Introduction}

Human papillomaviruses (HPV), double-stranded DNA viruses, are the commonest sexually transmitted disease agent worldwide presenting clinically as genital warts or existing asymptomatically in men and women [1]. It can lead to many mucocutaneous diseases which can be benign or malignant varying from common warts to malignancies. HPV is strongly associated with cervical precancer and cancer and strongly predicts its development. Cervical cancer which is the second most cancer in women all over the world, and is a unique cancer as it is totally attributable to the effects of an infectious virus, i.e., HPV [2]. India has one-fourth of cervical cancer of the world and almost all patients have high risk HPV infection [3]. It is difficult to cultivate HPV so diagnosis of HPV infection depends primarily

Manuscript received: $27^{\text {th }}$ September 2016

Reviewed: $10^{\text {th }}$ October 2016

Author Corrected: $20^{\text {th }}$ October 2016

Accepted for Publication: $1^{\text {st }}$ November 2016 on the detection of viral genome by molecular techniques or by cervical cancer screening by detecting abnormal cells in cervical smears (i.e., cervical cytology or Pap smears). However, problem with cervical cytology is that it is insensitive for the detection of cancer and precancerous lesions [4], many rounds of screening have to be done to achieve an effective result. HPVs have been divided into more than 200 genotypes based on DNA sequences, approximately 80 of which have been well characterized.

However, it is now found that almost all cervical cancers whether of the squamous or of the adenocarcinoma histologic types, are causally related to cervical infections by 14 oncogenic human papillomavirus (HPV) genotypes (HPV16, 18, 31, 33, 35, 39, 45, 51, 52, 56, 58, 59, 66, and 68) [5,6]. Despite the fact that prevalence of HPV is dependent of the 
geographical region HPV 16 is by far the most prevalent and oncogenic HPV type [7]. Typically HPV18, 45, 31 and 33 are the next most prevalent types but the order varies between geographical areas. In other areas, such as Asia, HPV58 and HPV52 are the next most common after HPV16 and HPV18 [8].

Overall prevalence of HPV in cervix is $10 \%$ higher in women of developing countries. HPV infection is most common in sexually active young females but cervical cancer is common in older women suggesting infection at younger age and slow progression to cancer [9].

However, HPV genotype, persistent infection, coinfection, number of sexual partners, age, parity, long term use of oral contraceptives are important factors which will determine whether or not a woman infected with HPV will develop cervical cancer [9]. So the present study was undertaken to evaluate the distribution of HPV genotypes in a rural area of Punjab, with the aim of identifying the association of HPV genotypes with cervical cancer.

\section{Materials and Methods}

The retrospective study was conducted over a period of one and a half years i.e. from January 2015 to July 2016 on women attending obstetrics and gynaecology department of a tertiary care hospital. One hundred eighty three consecutive scrape samples or cervical brushings were collected from women presenting with any type of cervical lesions such as chronic cervicitis, endocervicitis, cervical erosions, cervical laceration, cervical polyp, leukoplakia of cervix and basal cell hyperplasia of cervix. The cervical brushings collected from patients were stored at $4^{\circ} \mathrm{C}$ after collection, to be processed within 2 weeks.

\section{Exclusion Criteria}

1. Patients who had intercourse $24 \mathrm{hrs}$ prior to the test.

2. Patients during menstrual period Hybribio human papilloma virus genoarray test kit was used which uses the combination of both polymerase chain reaction and flow through hybridisation technology for the qualitative detection and determine the specific HPV type present by genotyping 21 types of HPV DNA in cervical specimens. It can genotype the following HPV risk groups:

High Risk: HPV 16, 18, 31, 33, 35, 39, 45, 51, 52, 56, $58,59,66,68$

Low Risk: HPV 6, 11, 42, 43, 44

Undetermined Risk: HPV 53, CP8304

The assay was performed according to the manufacturer's protocol. DNA was extracted from the clinical sample using Hybribio DNA extraction kit. PCR was performed with a reaction volume of $25 \mu 1$ containing $1 \mu 1$ of DNA template, $23.25 \mu 1$ of PCR mix and $.75 \mu 1$ of DNA Taq polymerase in a applied bio systems Perkin Elmer 9600, GeneAmp PCR system 9700, PTC-200, EPPENDORF master thermal cycler.

The amplification protocol was as follows: $9 \mathrm{~min}$ of denaturation at $95^{\circ} \mathrm{C}$, and 40 cycles of $20 \mathrm{~s}$ of denaturation at $95 \mathrm{C}, 30 \mathrm{~s}$ of annealing at $55^{\circ} \mathrm{C}$ and 30 s of elongation at $72^{\circ} \mathrm{C}$, followed by final extension for $5 \mathrm{~min}$ at $72^{\circ} \mathrm{C}$. Then it was incubated at $4^{\circ} \mathrm{C}$. The amplicon were subsequently denatured and subjected to hybridisation.

The assay utilises a flow through hybridisation technique by actively directing the targeting molecules towards the immobilized probes within the membrane, with the complementary molecules being retained by the formation of duplexes.

After a stringent wash, the hybrids were detected by the addition of streptavidin-horseradish peroxidase conjugate (provided with the kit), which binds to the biotinylated PCR products, and a substrate (nitro blue tetrazolium-5-bromo-4-chloro-3-indolylphosphate) to generate a purple precipitate at the probe dot.

The results were interpreted using direct visualisation. After hybridisation, the presence of positive result for both the "internal control" and the "biotin" dots within the membrane indicated that the isolated DNA was of good quality, the enzyme conjugate was valid, and the hybridisation process was proper.

Demographic and clinical data of the patients with cervical lesions was recorded.

\section{Results}

Out of 183 cervical brushings collected over a period of one and a half years, $22(12 \%)$ were positive for HPV genotypes. Among the latter, HPV18 genotype was observed in 12 (54.5\%), HPV16 genotype in 3 (13.6\%) and HPV53 genotype in $2(9.09 \%)$ as shown in Table 1. One of the genotypes 68, 52, 39, 33, 59 and 56 were present in rest of the samples. 
Research Article

Table 1: Prevalence of various HPV genotypes in HPV positive patients.

\begin{tabular}{|c|c|c|}
\hline S.No. & Type of Genotype & Number of Patients \\
\hline 1. & 18 & 12 \\
\hline 2. & 16 & 03 \\
\hline 3. & 53 & 02 \\
\hline 4. & $56 \& 59$ & 01 \\
\hline 5. & 52 & 01 \\
\hline 6. & 68 & 01 \\
\hline 7. & 33 & 01 \\
\hline 8. & 39 & 01 \\
\hline & & 22 \\
\hline
\end{tabular}

Table- 2: Distribution \& HPV positivity of patients according to their age group.

\begin{tabular}{|c|c|c|c|}
\hline Age Group & No. Of Patients & HPV +ve & HPV -ve \\
\hline Less than 30yrs & 21 & $1(4.8 \%)$ & $20(90.9 \%)$ \\
\hline $30-40 y r s$ & 108 & $15(13.8 \%)$ & $93(86.1 \%)$ \\
\hline $41-50$ & 41 & $5(12.2 \%)$ & $12(87.8 \%)$ \\
\hline $51-60$ & 13 & $1(7.7 \%)$ & $161(87.9 \%)$ \\
\hline
\end{tabular}

Most commonly found HPV genotypes found in our study i.e. HPV 18 and 16, were the ones which fall under high risk group. Other than genotype 53 which is categorised under undetermined group, rest of the genotypes viz. 33, 39, 52, 56, 59, 68 and 33 observed in this study also belong to high risk group. Among these 22 positive patients, 15 (13.8\%) were in the age group of 30-40yrs as shown in table 2 .

\section{Discussion}

Considerable evidence already exists that the absolute risk for cervical precancer and cancer varies considerably among specific HPV genotypes. Persistent infection with high-risk HPV types is an important cause of cervical cancer [10,11]. However, early detection and subsequent effective treatment of HPV in precancerous lesions can prevent progression to cancer [12]. The present study shows that high risk genotypes 16 and 18 were present in females with cervical lesions which are in agreement with other studies [13,14]. High risk genotype 18 was the most common genotype in this study however in the study by Basu P et al genotype 16 was the most common [15]. They also found coinfection by genotypes 16 and 18 . In present study no such co-infection was observed, however coinfection by genotypes 56 \& 59 was observed. Genotypes 16, 18, 31, 33 , and 45 were the five most common types, detected in $87.1 \%$ of the total cases in the study by Basu P et al, however in the present study most commonly detected genotype was 18 , followed by 16 , and 53 constituting $72.7 \%$ of the total cases. HPV types 16 and 18 are consistently the two most common types in invasive cancer, globally. Comparing the prevalence of oncogenic HPV types in adenocarcinomas and squamous cell carcinomas and their precursors with that of women with normal cytology in one study, HPV16 has a preferential risk for both SCC and adenocarcinoma whereas HPV18 has a preferential risk for adenocarcinoma [16]. Large, rigorous case-series consistently find HPV16 the most prevalent and HPV18 the second most prevalent genotypes in SCC [5]; HPV18 the most prevalent and HPV16 the second most prevalent genotypes in adenocarcinomas [17], which are more often missed by cytology screening than SCC. Therefore, there is strong evidence that HPV16 and HPV18 are the most oncogenic type.

The highest proportion of positive HPV cases (16/22, $72.7 \%$ ) in our study corresponded to patients younger than 40 years, which was also observed by Morelva Toro in his study [18]. In the present study parity had no association with HPV infection which is in accordance with other studies [13,19]. The main limitation of our study is that these observations relied on a small number of cases. However, our findings will contribute to HPV knowledge in rural area of Punjab, India that will be useful for enforcing implementation of vaccine use and to augment screening strategies. Our data suggest that a vaccine targeting HPV genotypes 18 and 16 can help prevent cervical cancers in this region. 
The study by Munoz $\mathrm{N}$ et al suggested that vaccination against HPV16 and 18 could prevent almost $70-80 \%$ of invasive cervical cancers worldwide [20]. As the sensitivity and specificity of cytology-based screening is not optimum, and there is low screening coverage in most parts of India, immunization against the most prevalent high risk HPV genotypes affecting each region may represent the most effective means to longterm cervical cancer prevention [21].

A progress from cytology-based screening to HPVbased screening may prove useful in stratifying HPV positive women according to risk of developing prevalent precancerous and cancerous lesion, to determine the appropriate clinical management strategy. HPV testing has recently been investigated as an alternative to two diagnostic modalities (cytology and colposcopy) for the detection of persistent or recurrent disease. If HPV DNA is undetectable 6 to 8 months post treatment, the likelihood of post-treatment persistence or recurrence of disease is negligible.

\section{Conclusion}

In conclusion, for establishing effective preventive measures it is prudent to determine the types of HPV genotypes most commonly associated with cervical cell transformation in different geographical areas, as the current strategies for the prevention of cervical cancer and their precancerous lesions are based on the HPV genotyping and prophylactic vaccines [22,23,24,25].

Cervical cancer screening should depend on measuring the causal viral infection, oncogenic HPV, rather than the pleomorphic cellular changes caused by the infection [26].

Funding: Nil, Conflict of interest: None initiated, Permission from IRB: Yes

\section{References}

1. Burd EM. Human papillomavirus and cervical cancer. Clin Microbiol Rev. 2003 Jan;16(1):1-17.

2. Shanta V, Krishnamurthi S, Gajalakshmi CK, Swaminathan R, Ravichandran K. Epidemiology of cancer of the cervix: global and national perspective. $\mathrm{J}$ Indian Med Assoc. 2000 Feb;98(2):49-52.

3. Speich N, Schmitt C, Bollmann R, Bollmann M. Human papillomavirus (HPV) study of 2916 cytological samples by PCR and DNA sequencing: genotype spectrum of patients from the west German area. J Med
Microbiol. 2004 Feb;53(Pt 2):125-8. DOI: 10.1099/ jmm. 0.05447-0.

4. Nanda K, McCrory DC, Myers ER, Bastian LA, Hasselblad V, Hickey JD, Matchar DB. Accuracy of the Papanicolaou test in screening for and follow-up of cervical cytologic abnormalities: a systematic review. Ann Intern Med. 2000 May 16;132(10):810-9.

5. Muñoz N, Bosch FX, de Sanjosé S, Herrero R, Castellsagué X, Shah KV, Snijders PJ, Meijer CJ; International Agency for Research on Cancer Multicenter Cervical Cancer Study Group. Epidemiologic classification of human papillomavirus types associated with cervical cancer. N Engl J Med. 2003 Feb 6;348(6):518-27.

6. Cogliano V, Baan R, Straif K, Grosse Y, Secretan B, El Ghissassi F; WHO International Agency for Research on Cancer. Carcinogenicity of human papillomaviruses. Lancet Oncol. 2005 Apr; 6(4):204.

7. Clifford GM, Gallus S, Herrero R, Muñoz N, Snijders PJ, Vaccarella S, Anh PT, Ferreccio C, Hieu NT, Matos E, Molano M, Rajkumar R, Ronco G, de Sanjosé S, Shin HR, Sukvirach S, Thomas JO, Tunsakul S, Meijer CJ, Franceschi S; IARC HPV Prevalence Surveys Study Group. Worldwide distribution of human papillomavirus types in cytologically normal women in the International Agency for Research on Cancer HPV prevalence surveys: a pooled analysis. Lancet. 2005 Sep 17-23;366(9490):991-8.

8. Clifford GM, Smith JS, Plummer M, Muñoz N, Franceschi S. Human papillomavirus types in invasive cervical cancer worldwide: a meta-analysis. $\mathrm{Br} \mathrm{J}$ Cancer. 2003 Jan 13;88(1):63-73.

9. MolanoM, Van den Brule A, Plummer M, Weiderpass E, Poso H, Arslan A, et al. Determinants of clearance of human papillomavirus infections in Colombian women with normal cytology: a population based, 5 years follow-up study. Am J Epidemiol 2003; 158:486-494. DOI: 10.1093/aje/kwg171.

10. Walboomers JM, Jacobs MV, Manos MM, Bosch FX, Kummer JA, Shah KV, Snijders PJ, Peto J, Meijer CJ, Muñoz N. Human papillomavirus is a necessary cause of invasive cervical cancer worldwide. J Pathol. 1999 Sep;189(1):12-9.

11. Munoz N, Bosch FX, de Sanjose S, Herrero R, Castellsague X, Shah KV, et al. International agency for research on cancer. Multicenter Cervical cancer study 
Research Article

group. Epidemiological classification of human papilloma virus types associated with cervical cancer. $\mathrm{N}$ Engl J Med 2003Feb6; 348:518-27. DOI: 10.1056/ NEJMoa021641.

12. Spitzer M. Cervical screening adjuncts: recent advances.AmJ ObstetGynecol.1998Aug;179(2):544-56.

13. Duttagupta C, Sengupta S, Roy M, Senguota D, Bhatacharya $\mathrm{P}$, et al. Are Muslim women less susceptible to oncogenic human papillomavirus infection. A study from rural eastern India. Int $\mathbf{J}$ Gynaecol Cancer 2004; 14(2):293-303.

14. Aggarwal R, Gupta S, Nijhawan R, Suri V, Kaur A, Bhasin V, Arora SK. Prevalence of high--risk human papillomavirus infections in women with benign cervical cytology: a hospital based study from North India. Indian J Cancer. 2006 Jul-Sep;43(3):110-6.

15. Basu P, Roychowdhury S, Bafna UD, Chaudhury S, Kothari S, Sekhon R, Saranath D, Biswas S, Gronn P, Silva I, Siddiqi M, Ratnam S. Human papillomavirus genotype distribution in cervical cancer in India: results from a multi-center study. Asian Pac J Cancer Prev. 2009 Jan-Mar;10(1):27-34.

16. Bulk S, Berkhof J, Bulkmans NW, et al. Preferential risk of HPV16 for squamous cell carcinoma and of HPV 18 for adenocarcinoma of the cervix compared to women with normal cytology in The Netherlands. Br J Cancer 2006;94:171-5.

17. Castellsague $X$, Diaz M, de Sanjose S, et al. Worldwide human papillomavirus etiology of cervical adenocarcinoma and its cofactors: implications for screening and prevention. J Natl Cancer Inst 2006; 98: 303-15.

18. De Mendez MT. Prevalence of Human Papillomavirus (HPV) Genotypes and Multiple Infections in Routine Cervical Cancer Screening in a Spanish Regional Population. SOJ Microbiol Infect Dis 2013; 1(1):6.http://dx.doi.org/10.15226/sojmid.2013. 00105.

19. Lazcano-Ponce E, Herrero R, Muñoz N, Cruz A, Shah KV, Alonso P, Hernández P, Salmerón J,
Hernández M. Epidemiology of HPV infection among Mexican women with normal cervical cytology. Int J Cancer. 2001 Feb 1;91(3):412-20.

20. Muñoz N, Bosch FX, Castellsagué X, Díaz M, de Sanjose S, Hammouda D, Shah KV, Meijer CJ. Against which human papillomavirus types shall we vaccinate and screen? The international perspective. Int J Cancer. 2004 Aug 20;111(2):278-85.

21. Cuzick J, Arbyn M, Sankaranarayanan R, Tsu V, Ronco G, Mayrand MH, Dillner J, Meijer CJ. Overview of human papillomavirus-based and other novel options for cervical cancer screening in developed and developing countries. Vaccine. 2008 Aug 19;26 Suppl 10:K29-41. doi: 10.1016/j.vaccine.2008.06.019.

22. Saslow D, Solomon D, Lawson HW, Killackey M, Kulasingam SL, Cain J, Garcia FA, Moriarty AT, Waxman AG, Wilbur DC, Wentzensen N, Downs LS Jr, Spitzer M, Moscicki AB, Franco EL, Stoler MH, Schiffman M, Castle PE, Myers ER; ACS-ASCCPASCP Cervical Cancer Guideline Committee. American Cancer Society, American Society for Colposcopy and Cervical Pathology, and American Society for Clinical Pathology screening guidelines for the prevention and early detection of cervical cancer. CA Cancer J Clin. 2012 May-Jun;62(3):147-72. doi: 10.3322/caac. 21139. Epub 2012 Mar 14.

23. Trottier H, Franco EL. Human papillomavirus and cervical cancer: burden of illness and basis for prevention. Am J Manag Care 2006; 12: S462-S472.

24. FrancoEL, Cuzick J. Cervical cancer screening following prophylactic human papillomavirus vaccination. Vaccine 2008; 26: A16-A23.

25. No JH, Kim MK, Jeon YT, Kim YB, Song YS. Human papillomavirus vaccine: widening the scope for cancer prevention. Mol Carcinog. 2011 Apr; 50(4):24453. doi: 10.1002/mc.20657.

26. Castle PE. The potential utility of HPV genotyping in screening and clinical management. J Natl Compr Canc Netw. 2008 Jan;6(1):83-95.

\section{How to cite this article?}

Sharma P, Sharma S, Arti. Significance of Human Papilloma Virus genotyping in cervical cancer screening.Trop J Path Micro 2016;2(3):120-124.doi: 10.17511/jopm.2016.i03.07 